\title{
Networking for English Literature Class: Cooperative Learning in Chinese Context
}

\author{
Huiyin $\mathrm{Li}^{1}$ \\ ${ }^{1}$ Guangdong University of Foreign Studies, China \\ Corresponding: Huiyin Li, Guangdong University of Foreign Studies, China. E-mail: clara2006@126.com
}

Received: September 20, 2017 Accepted: November 23, 2017 Online Published: November 26, 2017

doi: 10.5539/elt.v10n12p219 URL: http://doi.org/10.5539/elt.v10n12p219

\begin{abstract}
This action research was conducted to investigate the efficacy of networking, an adjusted cooperative learning method employed in an English literature class for non-English majors in China. Questionnaire was administered online anonymously to college students after a 14-week cooperative learning in literature class in a Chinese university, aiming to study whether the proposed cooperative learning method was an effective method in literature class and how it would impact students. The results indicated that it was an effective instructional practice with benefits in academic study, accountability and social skills.
\end{abstract}

Keywords: networking, cooperative learning, literature class, action research

\section{Introduction}

College English is an umbrella term referring to English courses provided by Chinese universities to non-English major students (Li, 2016). It has long focused on linguistic aspects until the newly formulated Guidelines for College English Teaching (Li, 2016), a syllabus for national College English teaching. Different from previous national curriculum syllabi for College English stipulated by Chinese Education Ministry, Guidelines highlights both instrumentality and humanism of English study and advocates cultural studies by encouraging intercultural education. Guidelines aims at satisfying the requirements proposed by Outline of national medium and long-term education reform and development program (2010-2020), which are to cultivate college students' world outlook and global awareness, to enhance their humanistic capacities for knowledge innovation and personal development, as well as to prepare for opportunities and challenges in this globalized era ("Guidelines", n.d.).

To align with Guidelines, English Literature was set up in G University in South China to cultivate students' critical thinking, to promote their aesthetic appreciation, and to enhance their intercultural communication. Contents and teaching methods have been modified to meet student needs. Still problems exist, the most common of which are students' reticence in class, disinterest in group discussion, and their unfinished reading of the assigned literary works (talk with colleagues, March 6, 2017).

To address the problems listed above, an adjusted cooperative learning method was adopted in English literature class. As action research is considered an effective way to promote teachers' reflection on teaching and to improve teaching efficiency $(\mathrm{He}, 2016)$, the researcher, also the teacher of English Literature, conducted a 14-week action research among 163 non-English majors in G university. Aiming at investigating the efficacy of this adjusted cooperative learning model in literature class, the researcher attempted to bring vitality back to classroom and to cultivate students' interest in literature.

The contributions of this research are (1) implementing a novel cooperative learning method in English literature course in Chinese context, (2) studying the efficacy of the proposed cooperative learning method, and (3) studying the impact of the proposed learning method upon students.

\section{Theoretical Framework}

Cooperative learning is known as a most important active learning technique by grouping students together to accomplish both individual and group learning goals (Prince, 2004). It has many variants, such as the general cooperative learning model, jigsaw model and graffiti model (Kilbane \& Milman, 2014).

The roots of cooperative learning can be traced back to the 1960s' progressive movement in America. John Dewey, the advocate of progressive movement, proposed that learning was a social process and helped breed 
social interdependence theory. Social interdependence theory, as the conceptual framework for cooperative learning, posited that each individual's goals were affected by the action of others (Deutch, 1949), therefore, could drive students to work together to achieve goals, regardless of their colors.

Undergirded by social interdependence theory, cooperative learning was formally introduced into classrooms and widely used in academic contexts to promote racial integration and social equality. Due to its critical attributes, such as strong group dynamics and positive relationships, which impact student learning and development significantly, cooperative learning has since then progressed steadily to become popular among American teachers (Kilbane \& Milman, 2014) and has gradually been widely employed in the world (Johnson \& Johnson, 2009). Its popularity has attracted a plethora of researches into the studies of its components, procedures and outcomes, making cooperative learning one of the much-studied pedagogical practice (Slavin, 2002). These studies have confirmed its benefits, which are displayed in academic growth (Slavin, 2002; Johnson \& Johnson, 2009), such as improved academic achievement and critical thinking, in psychological health (Slavin, 2002; Nolinske \& Millis, 1999), such as enhanced self-esteem and lower level of stress and anxiety; and in social skills (Nagel, 2008; Lemming, 1992), such as more supportive relationship with classmates and the acquisition and enhancement of communicative skills.

Till now, cooperative learning has been identified as the most effective and successful instructional strategy (Johnson \& Johnson, 2009; Morgan, n.d.). Across grade levels and subject areas, regardless of cultures, student needs, and instructional forms, cooperative learning functions equally well. Central to the success are its five critical attributes (Kilbane \& Milman, 2014) .

The first is positive interdependence which is a sink-or-swim game. That is, everyone succeeds or fails together. Each member assumes a key role in the group and the success of the group work is decided by whether everyone succeeds in that role. It warrants the consideration of personal contribution to the group. Group goals or rewards force students to rely on each other to be successful at the task, thus create strong cohesive power by providing them an incentive to encourage and assist each other. Aronson and Patnoe (1997) argued positive interdependence could be promoted by distributing resources and tasks among group members so that every member had unique information and responsibilities for the completion of the project.

What comes next is individual accountability. It brings into limelight individuals' efforts in accomplishing the shared learning goals. Responsibilities increase when individual work influences overall group work. Slavin (1995) stated "cooperative learning has its greatest effects on student learning when groups are recognized or rewarded based on the individual learning of their members" (p. 41). A typical method to establish individual accountability is the teacher randomly requires a member to answer questions for the group. One important factor that influences this attribute is the size of the group. The larger the size is, the less individual accountability there is, and the less students communicate, as it is more difficult to identify personal contribution important to group success (Kerr, 2001). Nagel (2009) stated students in a group of four were more active in participating in group work.

Group processing is a third element. It allows group members to examine both individual and group contributions, practise their high-order thinking and social skills in order to come to a wiser decision to help achieve the group goal. Therefore, group processing engages members by evaluating personal contribution to the group, fosters self-esteem and positive relationship in the group, and improves their thinking by analyzing which action contributes to the goal and what action should be continued or changed. To promote group processing, teachers need to structure activities to allow members to discuss, to share, and to reflect.

Promotive interaction refers to the outcome of positive interaction, which involves any interactions beneficial to both individuals and the group, from social and emotional to intellectual exchanges, including "mutual help, exchange of resources, trust and effective communication" (Giles, Ashman, \& Terwel, 2008). Traditionally, promotive interaction takes place in a face to face manner, but it can also occur in online and hybrid learning environments by using web conferencing, online discussion boards, shared documents and online chats. It encourages direct interaction with each other and contributes to achieving group goals and personal development. It is a "two for one" deal.

The last attribute is the interpersonal and small group social skills. To have high-quality cooperative learning and to deal with stress and strains of doing so, group members should learn to use social skills appropriately. These skills include active listening, trust building, conflict resolution, leadership and agreeing to disagree, to name a few. Therefore, sufficient instruction or scaffolding is necessary. It is commendable if the instructor offers some examples of group processing to raise students' awareness of how to show respect and appreciation for each member's contribution. 


\section{Action Research Design}

Based on the five essential attributes of successful cooperative learning, I devised networking cooperative learning method and conducted an action research for one semester. I applied networking cooperative learning in my literature class for non-English majors for 14 weeks, attempting to redress students' overall disinterest in English literature and their lethargy in class participation. My research questions are:

1) Is networking an effective cooperative learning method in literature class?

2) How does this cooperative learning method affect students?

\subsection{Research Setting}

English literature incurs unpopularity among Chinese college students due to its impracticality in their prospective job market (Fan, 2008). Many a student show little interest in literature. They complain about comprehension difficulty caused by language and cultural backgrounds (Fan, 2008). This becomes even worse in a crowded regular literature English classroom for non-English majors. It is a commonplace that many students do not read literature texts at all (questionnaire, June 25, 2017), remain silent or fall into sleep in class (talk with colleagues, March 6, 2017).

Therefore, I regard rekindling students' interest in literature as the primary goal in my class. Emphasis is put on readers' response, especially individual's reading experience and interpretation of literary texts. Literary theories are seldom discussed for two reasons. One is obscure literary theories cannot help promote students' comprehension at their initial reading stage of English literature. English literature class in G University is intended as general education to cultivate students' literature appreciation capability and world outlook. They are not expected to make a living by literature. Obstacles, such as a wide vocabulary, invisible cultural dimensions, and different mindsets, often make English literature inaccessible to students. Therefore, literary theories exacerbate the situation by increasing students' study load and making them more anxious and less interested.

The other is literary theories might impede the cultivation of critical thinking. Critical thinking has been strongly advocated on campus as a primary goal of higher education. Literature-reading offers an effective way to cultivate critical thinking (Hakes, 2008), but literary theories might work against innovation by confining students to the framework of those theories, stifling and strangling students' budding interest and imagination.

\subsection{Participants}

I taught four literature classes weekly during the spring semester of 2017 academic year. Altogether I had over 160 sophomores, with an average size of 40 students in one class. Their majors ranged from trade and economics, accounting to insurance and computer sciences. They were arranged in a fixed class according to their majors upon their entrance to university and stayed with each other for four years till graduation. They had learned English for over ten years before they entered university. In the previous college academic year, they had learned Integrated English (a reading course aimed at improving students' listening, speaking, reading and writing), which was very similar to their previous English learning both in contents and learning patterns. Therefore, when they came to their second college year, their enthusiasm in English learning had become much dulled. They were reported to "slack off in class, fall into sleep, and play with their mobile phones" (Cai, 2012).

\subsection{Networking Cooperative Learning Method}

In order to reenergize students and to implement cooperative learning effectively in a crowded classroom, I devised networking cooperative learning method. The first thing I started with was grouping. The only requirement I imposed on grouping was four students in one group and they could not hang with the same study group as they did in their previous semester. My purpose was to motivate them to know about and learn from different peers. In compliance with the requirement at grouping, students voluntarily clustered themselves into their own study groups.

The second step was the preparation work of individual reading and group learning before class. What was required for each group was to (1) finish reading the literary works individually, (2) discuss and share within the group their problems, uncertainties, and their likes about the text, (3) write down on a piece of paper their designed questions they thought vital for the comprehension of the text as well as the questions they still had, together with their names and group number, and (4) take a photo of their discussion with their mobile phone and keep it for the instructor's checking in the forthcoming literature class.

The third step was the in-class discussion. Before discussion, I would briefly offer students some background information, attempting to inspire students to comprehend the text from another perspective and setting the stage for their discussion. I collected question lists from each group and gave them out randomly so that each group 
was given a question list from a different group. The rationale was to endow students with responsibility and honor in designing quality questions and to help them comprehend the literary text from different perspectives.

When students were engaged in their discussion, I began my busy work. I first checked their photos and gave them credits for group participation and discussion. Then I listened from group to group to facilitate their discussion and to identify students' problems and their strengths. Each member had to contribute their understanding to those questions and listened attentively to each other, as what would happen next was one of them would be chosen as the speaker for the group to go to the question-list group and answer those questions independently. My requirement at this step was group members should take turns to be the group speaker. The remainder members would have a visitor, the speaker from another group, who would answer all the questions listed on their question list. In the meanwhile, they agreed or disagreed, discussed and even challenged each other. Any unresolved questions would be addressed at the summary stage.

As a summary, the instructor would question the whole class based on the literary text to check student comprehension and lead students to be clear of those unresolved questions. In this phase, anyone who shared their views would earn credits. Figure 1 demonstrates how students networked with each other as well as the instructor's role in class, which gave the name to this cooperative learning method.

It is apparent the features of networking cooperative learning method are as follows:

- The instructor has been "decentralized" by placing groups of students in the limelight.

- The role of the instructor has changed from being a lecturer to giving instructions, supervising group discussion, assisting and enlightening students, and managing time.

- Five elements of cooperative learning have been holistically integrated in this approach to guarantee that each member can finish the reading, can contribute to discussion and help each other to accomplish the assignments.

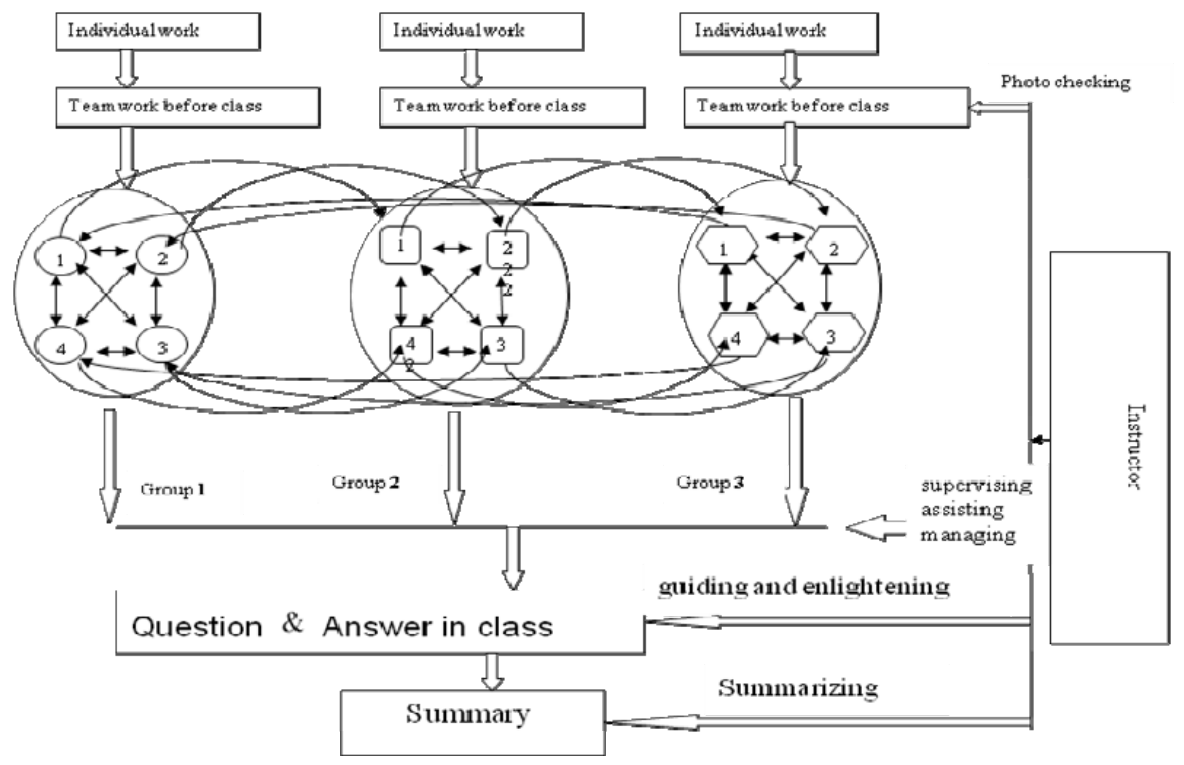

Figure 1. Networking for English Literature class

\subsection{Assessment of Student Performance}

Assessment, as an indispensable component in learning, plays an important role as far as students are concerned. Gibbs and Simpson (2004) suggested that assessment decided students' study focus, defined their engagement with learning tasks, and influenced their understanding and future learning.

Besides traditionally summative assessment such as quiz and final exam, I included a variety of formative assessment, which had been articulated at the beginning of the semester and carried out consistently throughout the semester. Photos of their discussion and question lists before class would earn participation points (ten points each time); group discussion in class could get group performance credits (ten points each time) shared by all the group members; answering at the summary section could gain individuals credits (five points each time); 
questioning group would evaluate the answering group's performance by grading them from five points (most satisfactory) to one (least satisfactory) with one paragraph briefly explaining why they scored them so. Additionally, I referred to the Effort and Achievement Comparison Rubric from Herrera, Cabral, and Murry (2013) (see Appendix B) and invited students to assess their efforts and achievement at the end of each unit.

\subsection{Research Tool}

In order to test the efficacy of networking cooperative learning method, I designed a questionnaire (see Appendix A) with 30 multiple choice questions, focusing on five aspects: general comparison between without networking and with networking, academic learning, accountability, social skills, and grouping and assessment. By the end of one semester's class, I uploaded my questionnaire to Wenjuanxing, a free Chinese survey platform at https://www.wjx.cn/, and invited students to participate at their own free will. As questionnaire was filled out anonymously and voluntarily online any time within one week, students felt at ease to answer those questions. Their concerns about safety and privacy could be dismissed. Among my 160 students, 137 filled out questionnaire. When questionnaire was closed one week later, data were collected and processed automatically by Wenjuanxing. Based on the revealed results, I used Microsoft Excel to formulate the following figures in this paper in order to display the impact on students without and with networking cooperative learning method. Other results were displayed in tables presented in this paper.

\section{Results and Discussion}

The results were very encouraging which suggested the positive influence of networking on students. The results indicated a strong relationship between networking cooperative learning method and students' improved attitude to English Literature study. As was shown in Figure 2, 3 and 4, without the employment of networking cooperative learning method, over $40 \%$ of the students would not read literary texts, over $50 \%$ would not consult references nor discuss with classmates. With networking, the dominant part of the students (even as high as 95\%) finished required reading, consulted references on their own and consulted their classmates. We can conclude that networking greatly motivated students to fulfill their individual accountability.

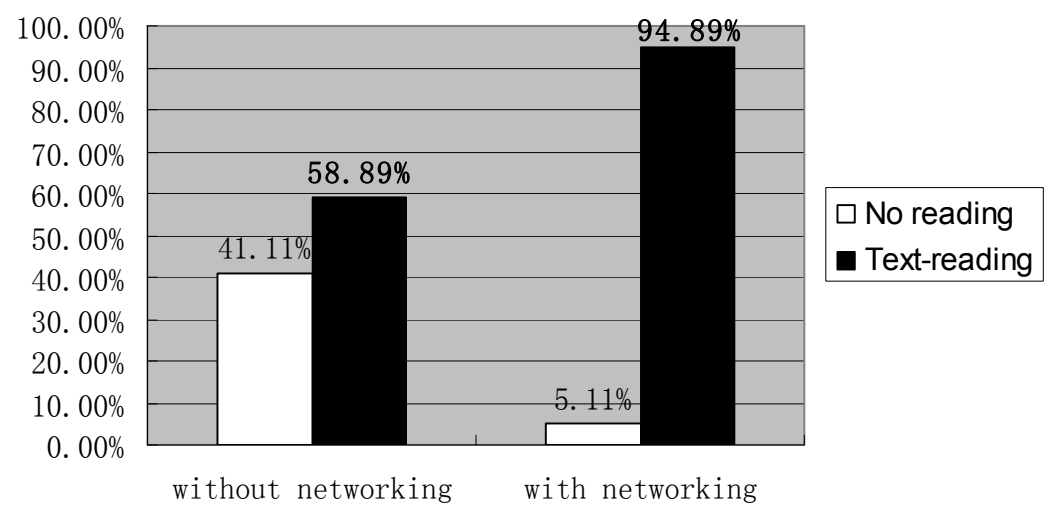

Figure 2. Comparison in text-reading without and with networking

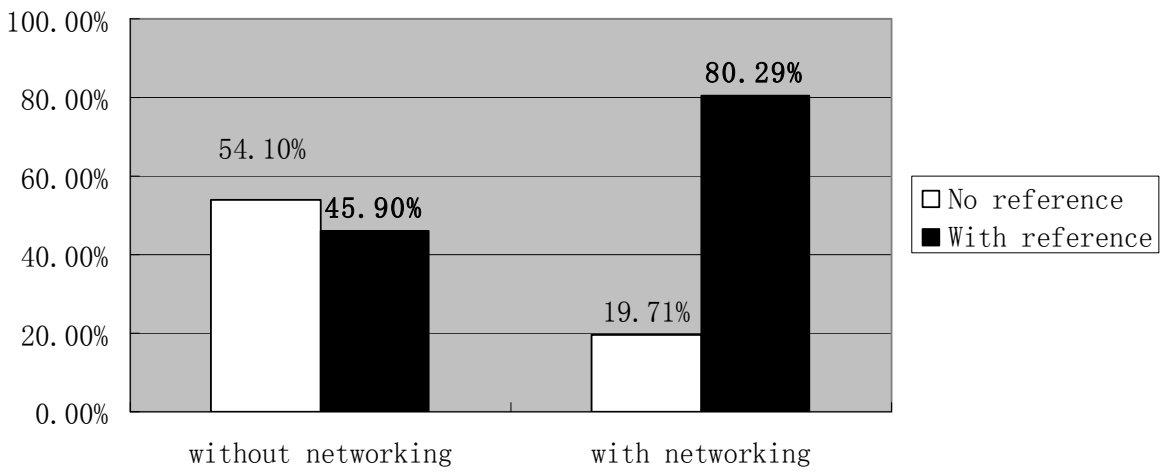

Figure 3. Comparison in reference without and with networking 


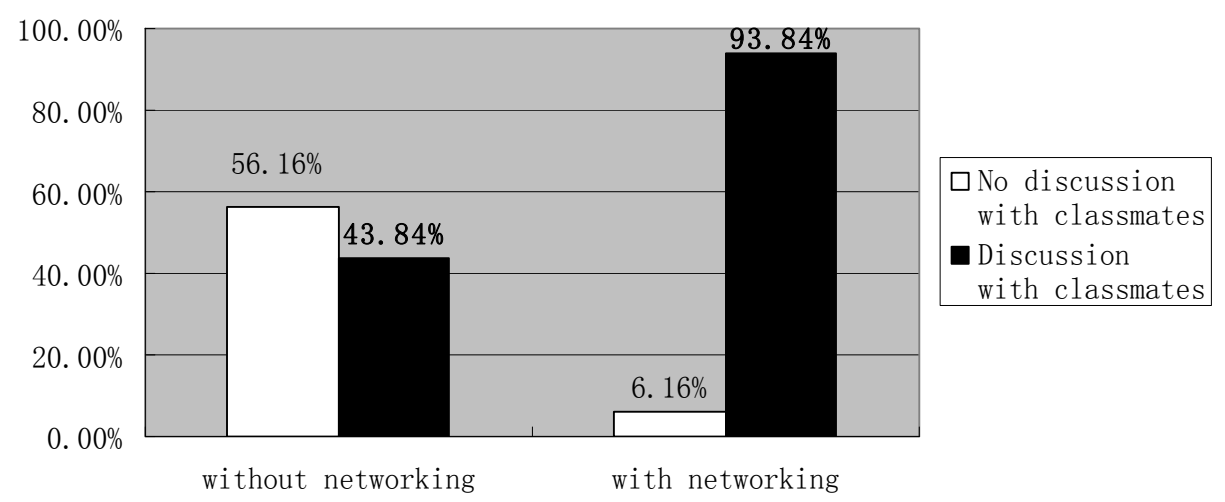

Figure 4. Comparison in discussion without and with networking

The relationship between positive interdependence and individual accountability inherent in successful cooperative learning explains the vast change in learning attitude. Social interdependence theory asserts that individual outcomes are influenced by their own and others' actions (Johnson \& Johnson, 2009). Therefore, "when individuals perceive they can reach their goals if and only if the other individuals with whom they are cooperatively linked also reach their goals" (Giles, Ashman, \& Terwel, 2008), positive independence motivates each other to make individual efforts in achieving their group goal, which embodied in students' reading of literary texts and reference-consulting before group discussion in order to improve their work quality beneficial for the accomplishment of their group goal.

When the structure of networking excludes free-riders, assessment methods also contribute to this joint enterprise. Self-assessment rubric helps students to understand more thoroughly the criterion of quality products and performance, which motivates each member to meet those criteria with greater drive. In addition, as the speaker's performance in the in-class discussion session represents the entire group's achievement, all members spared no efforts to arrive at a better answer which got rewarded with a high mark from their peer groups. Thus, no one dared to slack off to become the drag of the group. "Failing oneself is bad, but failing others as well as oneself is even worse" (Johnson \& Johnson, 2009) rang powerfully with every member.

Consistent with previous studies of the effect of cooperative learning, the results of this questionnaire displayed positive impact of networking on students' academic achievement, accountability and social skills. Table 1 showcases students' academic benefits from networking. When motivation was reinforced by positive interdependence and individual accountability, students' efforts paid off with improved comprehension. Gradually students learned to figure out their learning method and changed their learning attitude. In the meanwhile, group processing and promotive interaction promoted their thinking and deepened their comprehension. The four critical attributes of cooperative learning interacted with each other and generated positive academic outcomes of networking.

Table 1. Positive academic outcomes of networking

\begin{tabular}{ll}
\hline Positive academic impact of networking & Percentages of agreement \\
\hline Improved comprehension of literary texts & $91.1 \%$ \\
Improved attitude to learning & $92.14 \%$ \\
More engagement in discussion & $79.45 \%$ \\
Improved expressive ability in English & $68.49 \%$ \\
Improved learning method & $60.96 \%$ \\
Improved academic achievement & $82.19 \%$ \\
\hline
\end{tabular}

Table 2 displays students' improvement in accountability and the sense of collectivism or cooperation. This could be accounted for by the interplay between positive interdependence and individual accountability. By the time group members had accomplished their group goal, each had also achieved their individual learning goals. 
Table 2. Positive outcomes on accountability and cooperation of networking

\begin{tabular}{ll}
\hline Positive impact of networking on accountability and cooperation & Percentages of agreement \\
\hline The feeling of being in the same boat & $88.36 \%$ \\
Increased sense of accountability & $91.97 \%$ \\
Feeling happy about group achievement & $94.89 \%$ \\
Personal contribution to group work & $92.7 \%$ \\
Group members' contribution to group work & $84.25 \%$ \\
\hline
\end{tabular}

Table 3 presents a glimpse of the positive effect on social skills. Networking provided students with many chances to exchange with each other. In sharing and discussion, students picked up or practiced their social skills, where the other two critical attributes of cooperative learning---promotive interaction and interpersonal and small group social skills---were brought into full play and contributed to better understanding of and improved relationship with each other.

Table 3. Positive outcomes on social skills of networking

\begin{tabular}{ll}
\hline Positive outcomes on social skills of networking & Percentage of agreement \\
\hline Listening to others' opinions and discuss later when in disagreement & $86.86 \%$ \\
Willing to offer help and encouragement & $89.05 \%$ \\
Trust group members & $97.08 \%$ \\
Accommodating others' views with an open mind when wrong & $95.89 \%$ \\
Improved relationships among classmates & $93.43 \%$
\end{tabular}

In learning environment, $88.32 \%$ of students were satisfied with their grouping and nearly $65 \%$ students did not think instructors should intervene in group buildup, which clearly suggested their preference to choosing their own group members and opposition to instructors' imposition in grouping. The overwhelming majority (81.02\%) of students preferred to sit around tables for discussion, rather than in rows.

Finally, as high as $91.97 \%$ of students showed satisfaction with the current assessment methods. A variety of methods were applied to assess students' efforts and performance at each step, which impressed students that this was a fair way to truly reflect their efforts they put in, therefore, could present a better picture of their overall achievement. These assessment methods also contributed to their energized work in the networking cooperative learning method.

From the positive effects listed above, it is promising that networking cooperative learning strategy can become an effective instructional method for college English literature course. It provided students proper stimulus and motivation, successfully engaged students in text-reading and meaningful discussion, and helped students to grow cognitively, emotionally and socially.

\section{Implications}

Networking was presented for disinterested students in a crowded English classroom in China. Its success informs instructors that cooperative pedagogy needs adjustment to produce positive outcomes. As long as activities are structured properly, and assessment is conducted with appropriate methods, students can resume their interest and benefit from cooperative learning.

Besides the group size, individual preparation and group cooperation before class played a vital role in the success of networking cooperative learning. Like many courses in Chinese college classrooms, literature course confronts the same dilemma. On one hand, we need to cover rich contents within fixed class time; on the other, we need to give sufficient time for students to think, to discuss and to share. Networking provides a potential solution. Assigning reading and thinking before class, networking guarantees quality time for students to share, interact and express in class. What is more significant in networking is the important attributes demonstrated by students, such as how to deal with disagreement constructively and with mutual respect, which are important to global citizenship. Networking reduces students' fear or anxiety of literature in English and motivates many 
students to take an interest in literature. By the end of the term, dozens of students mentioned to me that they planned to read original literature works in their spare time, which indicated I had achieved my goal in this literature class. This method could also be employed in other crowded English classrooms in similar context.

Another implication is the usage of mother language. From time to time in class discussion, students turned to mother language to express their ideas, especially when they were eager to express their ideas or convince others, which explained why improved English expression reaped a relatively smaller success in Table 1. I usually allowed them to do so. But how much should be allowed still puzzles me. Since I personally value individual experience, I think occasional usage of Chinese in expression is acceptable.

Besides, teachers' educational ideology needs to be updated. The entire Chinese educational setting has been accustomed to respect for authority for a long time. Both teachers and students tend to expect a definite answer from authority. To encourage students to share their ideas and to cultivate their critical thinking, teachers need to embrace an open mind and encourage students to think freely and to speak out freely. Only in this way, reticence typical among Chinese students can be gradually improved.

\section{Acknowledgements}

The research was sponsored by Guangdong Planning Office of Philosophy and Social Science, Guangdong Province (GD16XWW32). The author gratefully acknowledges all students' help and participation in taking the online questionnaire.

\section{References}

Aronson, E., \& Patnoe, S. (1997). The jigsaw classroom. New York: Addison Wesley Longman.

Cai, J. (2012). A way out for EFL at tertiary level education in mainland China. Shanghai: Publish house of Shanghai Jiaotong University.

Deutsch, M. (1949). A theory of cooperation and competition. Human Relations, 2, 129-152. https://doi.org/10.1177/001872674900200204

Fan, Q. (2008). Anxiety and salvation in the teaching and learning of English literature. Foreign Languages in China, 5(1), 79-82.

Gibbs, G., \& Simpson, C. (2004). Conditions under which assessment supports students' learning. Learning \& Teaching in Higher Education, 1(1), 3-31.

Giles, R. M., Ashman, A., \& Terwel, J. (2008). The teacher's role in implementing cooperative learning in the classroom. New York: Springer. https://doi.org/10.1007/978-0-387-70892-8

Guidelines for College English teaching. (n.d.). Retrieved from http://www.360doc.com/content/17/0203/14/413468_626210661.shtml

Hakes, B. (2008). When critical thinking met English literature. Oxford: How to books.

He, X. Y. (2016). An action research on improving non-English majors' English writing by basic sentence pattern translation drills. English language teaching, 9(1), 142-147. https://doi.org/10.5539/elt.v9n1p142

Herrera, S. G., Cabral, R. M., \& Murry, K. G. (2013). Assessment accommodations for classroom teachers of culturally and linguistically diverse students. Boston: Pearson.

Johnson, D., \& Johnson, R. (2002). Learning together and alone: overview and meta-analysis. Asia Pacific Journal of Education, 22, 95e105. https://doi.org/10.1080/0218879020220110

Johnson, D. W., \& Johnson, R. T. (2009). An educational psychology success story: social interdependence theory and cooperative learning. Educational Researcher, 38(5), 365-379. https://doi.org/10.3102/0013189X09339057

Kerr, N. (2001). Motivation gains in performance groups: aspects and prospects. In J. Fargas, K. Williams, \& I. Wheeler (Eds.). The social mind: Cognitive and motivational aspects of interpersonal behavior (pp. 350-370). New York: Cambridge University Press.

Kilbane, C., \& Milman, N. (2014). Teaching models: Designing instruction for 21st century learners. New York, Pearson.

Lemming, J. S. (1992). The influence of contemporary issues curricula on school-aged youth. In C. Grant (Ed.), Review of research in education (pp. 111-161). Washington, DC: American Educational Research Association. https://doi.org/10.2307/1167298 
Li, H. Y. (2016). On guidelines for College English teaching and challenges for College English teachers. English language teaching, 9(1), 77-87. https://doi.org/10.5539/elt.v9n1p77

Morgan, B. M. Cooperative learning: Teacher use and social interaction. Retrieved fromhttps://www.researchgate.net/publication/242529125_COOPERATIVE_LEARNING_TEACHER_US E_AND_SOCIAL_INTEGRA__TION

Nagel, P. (2008). Moving beyond lecture: cooperative learning and the secondary social studies classroom. Education, 128, 363-368.

Nolinske, T., \& Millis, B. (1999). Cooperative learning as an approach to pedagogy. American Journal of Occupational Therapy, 53, 31-40. https://doi.org/10.5014/ajot.53.1.31

Patrice, R. L., \& Cindy, S. (1997). Support for democratic schooling: classroom level change via cooperative learning. Action in Teacher Education, 19(1), 28-38. https://doi.org/10.1080/01626620.1997.10462851

Prince, M. (2004). Does Active Learning Work? A Review of Research. Journal of Engineering Education, 93(3), 223-231. https://doi.org/10.1002/j.2168-9830.2004.tb00809.x

Salehizadeh, M. R., \& Behinaein, N. (2014). Effects of cooperative learning plus inquiry method on student learning and attitudes: a comparative study for engineering economic classrooms. European Journal of Engineering Education, 39(2), 188-200. https://doi.org/10.1080/03043797.2013.838542

Slavin, R. E. (1990). Research on cooperative learning: consensus and controversy. Educational Leadership, 47(4), 52-54.

Slavin, R. E. (1995). Cooperative learning: Theory, research, and practice. Boston: Allyn and Bason.

\section{Appendix A: Questionnaire on networking cooperative learning method}

\section{1) General comparison questions regarding networking}

1. Without using networking, would you read texts?
A. No
B. Yes

2. Without using networking, would you consult references before class?
A. No
B. Yes

3. Without using networking, would you discuss the text with classmates as you did in this semester?
A. No
B. Yes

With networking in this semester:

4. Did you finish reading texts?
A. No
B. Yes

5. Did you consult references to help your understanding of the texts?
A. No
B. Yes

6. Did you interact with classmates regarding the reading more than before?
A. No
B. Yes

\section{2) Academic impact on students}

7. Has networking improved your comprehension of the texts?
A. No
B. Yes

8. Has networking improved your attitude to learning?
A. No
B. Yes

9. Has networking engaged you more in group discussion?
A. No
B. Yes

10. Has networking improved your expression in English?
A. No
B. Yes
11. Has networking helped you to improve your learning methods? 

A. No
B. Yes

12. Do you think networking will improve your academic achievement?
A. Yes, very much.
B. No, not at all.

\section{3) Impact on accountability}

13. Did you have the sense of being in the same boat in doing group work?
A. Yes
B. No
14. Do you think networking enhanced your accountability?
A. Yes
B. No
15. How did you feel when your group achieved success?
A. Very happy.
B. I don't care.

16. How was your participation like in the group work?
A. I participated in group discussion each time
B. I participated from time to time.
C. I sometimes participated.
D. I seldom participated in group discussion.

17. Did other members actively participate in group discussion?
A. Yes
B. No

\section{4) Impact on social communication}

18. Has networking increased your understanding of your classmates?
A. Yes
B. No

19. What would you do when you disagree with your classmates?

A. Insist on my own view no matter what others' views are.

B. Pretending to accept others' views, but still insist on my own ideas.

C. Listen to others' views with an open mind and discuss with them afterwards.

20. Are you willing to offer help and support to group members in group work?
A. Yes, I'd love to.
B. I can help if they ask
C. Not at all.

21. Do you trust your group members?
A. Yes
B. No

22. How often did you interact with your team members?
A. Very often
B. Occasionally
C. Not at all

23. What would you do when others critiqued your views?
A. Listen with an open mind.
B. Very angry.
C. Disagree with them.
D. I don't care.

24. Has networking improved your relationship with each other?
A. Yes
B. No

\section{5) Grouping and assessment}

25. How did you build up your group?
A. The instructor did that for us.
B. We were group members in the previous year.
C. We built our own group for this course.
D. We were the last four students and had to stay together.

26. Are you satisfied with your grouping?
A. Yes
B. No
27. Do you want your instructor to group you? 

A. Yes
B. No

28. Which seating do you prefer in class?

A. To sit in a circle

B. To sit in a row

C. I don't care.

29. Do you appreciate the current assessment system?
A. Yes
B. No

30. Do you wish your instructor to use networking more often in teaching?
A. Yes
B. No

\section{Appendix B: Effort and achievement comparison rubric}

Name__ Date

Assignment

\begin{tabular}{|c|c|}
\hline \multicolumn{2}{|l|}{ Effort \& Achievement Comparison Rubric } \\
\hline Effort & Achievement \\
\hline $\begin{array}{l}5=\text { I put maximum effort into this task. I stretched } \\
\text { myself to complete this task despite its difficulty. I } \\
\text { approached task difficulties as challenges to be } \\
\text { overcome. I built new capacities as a result of } \\
\text { confronting these challenges. }\end{array}$ & $\begin{array}{l}5=\mathrm{I} \text { exceeded the objectives of this task. } \\
4=\mathrm{I} \text { met all of the objectives of this task. }\end{array}$ \\
\hline $\begin{array}{l}\text { 4= I put exceptional effort into this task. I stretched } \\
\text { myself to complete this task despite its difficulty. I } \\
\text { approached task difficulties as challenges to be } \\
\text { overcome. }\end{array}$ & $\begin{array}{l}3=I \text { met at least half of the objectives of this task. } \\
2=I \text { met less than half of the objectives of this task. }\end{array}$ \\
\hline $\begin{array}{l}3=\text { I put moderate efforts into this task. I stretched } \\
\text { myself to complete this task despite its difficulty. I } \\
\text { approached task difficulties as challenges to be } \\
\text { overcome. } \\
2=\text { I put average effort into this task. I stretched myself } \\
\text { to complete this task despite its difficulty. } \\
\text { 1= I put limited effort into this task. }\end{array}$ & $1=\mathrm{I}$ did not meet the objectives of this task. \\
\hline $\begin{aligned} \text { Scale: } 5 & =\text { Excellent } \\
4 & =\text { Outstanding } \\
3 & =\text { Good } \\
2 & =\text { Improvement needed } \\
1 & =\text { Unacceptable }\end{aligned}$ & \\
\hline
\end{tabular}

\section{Copyrights}

Copyright for this article is retained by the author(s), with first publication rights granted to the journal.

This is an open-access article distributed under the terms and conditions of the Creative Commons Attribution license (http://creativecommons.org/licenses/by/4.0/). 